\title{
STUDY ON THE INFLUENCE OF HUMAN RESOURCES MANAGEMENT ON PATIENT SATISFACTION
}

\author{
Alina-Georgiana PETRE ${ }^{\text {* }}$ \\ ${ }^{a}$ Bucharest University of Economic Studies, Romania
}

DOI: $10.24818 / \mathrm{IMC} / 2020 / 04.17$

\begin{abstract}
This research paper aims to expand the knowledge regarding the issue of the influence of human resource management on patient satisfaction, considered a priority for safety and quality of life. The present study structures, synthesizes and analyzes relevant information from the literature in the field of human resources management in the health sector, as well as possible correlations between it and patient satisfaction. The approach is multilevel: studying the particularities of the health system, especially in Romania, identifying alternative solutions to amplify the role of human resources management in order to improve patient satisfaction and thus the quality of health services. It study aims to contribute to the development of literature on this topic and, in conclusion, highlights how human resource management can capitalize on its potential influence on the quality of health services.
\end{abstract}

KEYWORDS: health care services, human resource management, patient satisfaction, quality.

\section{INTRODUCTION}

Quality services and customer satisfaction have become increasingly important phrases nowadays, and management has developed so that it can meet these requirements they incur. However, important shortcomings regarding customer satisfaction are still present and one of the branches of management that can help fill the gaps is human resources management.

The presence of human resources management in the life of organizations is necessary for the development of effective strategies that lead to achieving the objectives of organizations by preparing, retaining and capitalizing on human potential. Human resource management is also present in all national systems of society, and one of the most important systems whose operation is based on human capital is the health system.

Therefore, to function, health systems need staff, financial resources, information, technology but also general guidance and regulations so that they can provide services appropriate to the needs of patients.

The importance of the health system is well known in society and all states admit that to improve the health of the world's population, political regulations are needed to support health systems to strengthen them and make them effective and able to cope with prevention. and the fight against various diseases and to be able to offer quality medical services regardless of the type or age of the population and regardless of the area in which they live (Cooke and Bartram, 2015).

The current health care crisis caused by the COVID 19 pandemic, which has affected almost every country in the world regardless of the area, has highlighted the shortcomings and limitations of the health care system around the world.

\footnotetext{
* Corresponding author. E-mail address: alina.petre1010@gmail.com
} 
The purpose of this article is to investigate the likely influence of human resource management on patient satisfaction and to identify new methods related to this field that can improve the quality of health services.

In accordance with the proposed purpose, the article is structured in two major chapters: the first chapter is dedicated to the presentation and explanation of the basic concepts used in the study, according to the literature. The second chapter resumes the basic idea of the study, that of the probable influence of human resources management on patient satisfaction by presenting the position of the Romanian health system at the EU level, following that in the second part of the chapter to establish a series of priorities for human resource management that could help to improve patient satisfaction.

\section{CONCEPTUAL CLARIFICATIONS NECESSARY FOR THE STUDY}

70 years ago, the first health system based on the Bismarck insurance model was created, a few years later the right to health was included in the Universal Declaration of Human Rights (1948) highlighting the fact that everyone has the right to a level adequate living, health and well-being for himself and his family. As health is the most valuable of each of us, the features of the health system have been some of the most important and controversial reasons to study.

That is why it is important to understand what a health system consists of, what is the interaction between management and the health system and what is the impact of human resource management on the health system. So when we talk about the health system we do not only refer to medicine, diagnosis and treatment of patients but also to management, communication, administration, and among the branches of management that has a strong impact on the quality of medical services is human resources management, the process following which employees achieve the desired level of satisfaction, and the organizations to which they belong achieve their goals by harmonizing four elements: environment, organization, position and employee (Deaconu et al., 2004), because the main resource is human capital, the individual, the productive potential of his knowledge, behaviors, experience and intelligence (Brînduşoiu, 2012), in our case, the specialist.

An overview requires mentioning the features of human resources management. Human resources management is strongly influenced by value systems, social devices, labor legislation, or the structure of the organization (Radu et al., 2003). Among the influencing factors of human resources management, we would like to mention employee competence, employee satisfaction, employee performance, organizational climate, etc.

From previous research, we found that there is a close link between customer satisfaction and the influencing factors of human resources management such as employee job satisfaction, employee performance, employee attitude. Through studies conducted in education systems with data collected from 298 schools in the USA, a direct correlation was observed between the satisfaction of beneficiaries and organizational performance, through the performance of the organization understanding a factor under the influence of human resources management (Ostroff, 1992).

From another study based on investigations in 351 small companies belonging to the same market segment, we find that the results highlighted the significant indirect effects that human resource management has on customer satisfaction and identified a social context model as an impact of human resources management practices on organizational objectives (Rogg et al., 2001).

The influence of human resources management on customer satisfaction was also studied in the hotel and restaurant sector, the result of the study being focused on the impact that human resources practices have on customer satisfaction, through a positive influence of the work environment, positive emotions resulting from work experience (Charles-Pauvres, 2020).

Another interesting research on human resource management was conducted at Cornell University's Center, which highlighted the link between satisfaction and human resource management. The features based on which this analysis was performed being based on the facial expression of the 
employees, the choice of words, the ethical nuances that the staff uses can create a good impression on the clients. So the conclusion was that the human success strategy used to obtain customer satisfaction depends on attention to detail (Kiger, 2002).

Another recent study of a Taiwanese company with more than 28,000 employees revealed the crucial capability that human resource management has for improving the organization's performance by achieving customer satisfaction (Chuang et al., 2015). The study aimed to propose an integrated model that highlights the causal variables of human resource capacity and customer satisfaction. The model is based on the results obtained from the study based on the distribution of 400 questionnaires sent by e-mail to the employees of the analyzed company; the response rate was $85.25 \%$. The model thus obtained was materialized by the diagram illustrated in the figure below which highlights the direct link between the capacity of human resources management and the organization's objectives, customer satisfaction, the efficiency of the organization, all these three factors being generators of service quality.

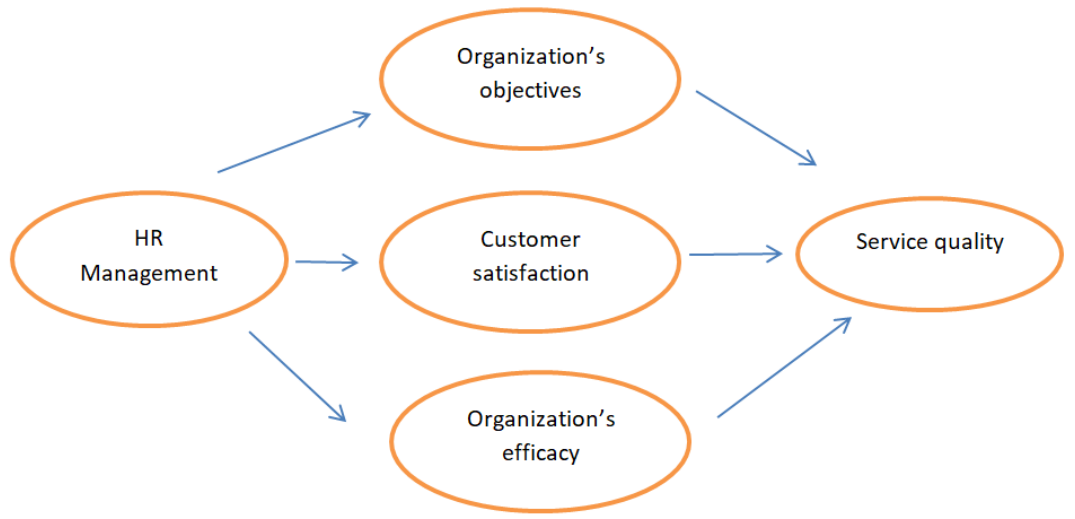

Figure 1. Research model

Source: adapted from Chuang et al. (2015, p.5)

In order to understand the concept of quality, we retain all the characteristics of a good or service through which it responds to the customer's need given its destination and the customer's intention to use it. Quality is considered to have several elements: staff quality, performance, practical application of management and human resources policies. To ensure a high quality, human resources management ensures a high quality of recruitment, training of human resources evaluation and setting of objectives (Torrington, 2003).

We also know quality cannot be achieved without competent human resources. Implementing a quality management system without having well-trained employees is useless, but by practicing a strategy in the field of human resources management to ensure quality human resources then we can get the expected result (Rusu \& Voicu, 2001). In this context, quality management was very successful through its implementation in organizations, from a specialized study conducted in production factory we find a direct link between human resource management and quality: a quality management model was created based on human resources, on control processes, on the connections with the clients and the result of these tests highlighted the existence of some direct, prominent influences on the clients' satisfaction as well as on the conformity of the quality (Forza \& Filippini, 1998).

Customer satisfaction was explained based on two philosophical perspectives: through marketing and total quality management. Marketing refers to a company that serves its employees while its internal services focus on employees who help each other (Marshall et al., 1998). Mohrw-Jackson (1991) later argued in his studies that in fact internal marketing and internal services are complementary with a common goal that is to improve the level of employee satisfaction. He 
investigated how human resource management can develop and maintain a customer-oriented employee attitude.

Another study by David E. Bowen (1996) showed how human resource management can simultaneously influence internal and external factors, customer satisfaction. The study was based on the characteristic factors of human resources management such as employee motivation and performance of employees able to provide quality services.

Because we are talking about motivating employees, Mihaela Dogaru and Valentina Zaharia (2016) reminded that in order to ensure the motivation of the staff, it is required first of all to act on the satisfaction of the primary needs. Motivation must start by solving the factors of dissatisfaction: salary and working conditions.

From the research done by Narcis Copcă (2020) we find that both the motivation and satisfaction of specialists in the hospital system are factors that must be regularly monitored and evaluated, finding out the opinion and proposals of employees regarding working conditions, the problems they face in the job, to the shortcomings encountered, to the internal but also external changes that impacted the development of the activity, as well as any other external or internal changes that influence the activity of the hospitals, influence the level of professional satisfaction of the specialists. If all these aspects are followed to have a positive impact on the medical staff, then it also spreads on the quality of the services they provide for their patients. This information collected from the staff, corroborated with studies on patients' opinions on medical services are vital for the motivation and professional satisfaction of medical staff and are supported by ensuring a very good medical endowment, good working conditions, safety and comfort, medical staff, sustained health, continuous professional development, modern leadership style, participatory, flexible, valorizing, collaboration, understanding, respect, participation in projects.

The correlation between service quality and customer satisfaction was also studied and demonstrated through the study of Chuang et al. (2015), who explains how employees who have a positive attitude are inclined to show altruistic behaviors, support and attention to the customer. In opposition to this study, another feature is highlighted by Jerry D. Rogers's study (1994) shows that unhappy, dissatisfied employees are unable to deliver excellent quality services to achieve customer satisfaction.

The purpose of this study is to identify ways in which human resource management could improve patient satisfaction, which is why we sought the results of specialized studies conducted in health systems.

Patient satisfaction is one of the main goals of health systems, thus its importance has increased over time, while the system has to deal with increasingly demanding demands such as lack of specialized personnel, lack of equipment, etc. Therefore, a recent study aimed to analyze how human resource management can help reduce shortages of hospital staff and how it can influence increased patient satisfaction (Wild et al., 2017). Another analysis was to establish the extent to which human resource management decisions to fill short-term vacancies through temporary staffing may affect patient satisfaction. The study was based on questionnaires sent to 732 hospitals in Germany, comprising 436,848 patient satisfaction assessments. The result was that human resource management reduces the rate of specialized staff shortages in the medical field while demonstrating the direct link between the lack of specialists and patient satisfaction. Also, the use of temporary employees decreases patient satisfaction (Charles-Pauvers, 2020). 


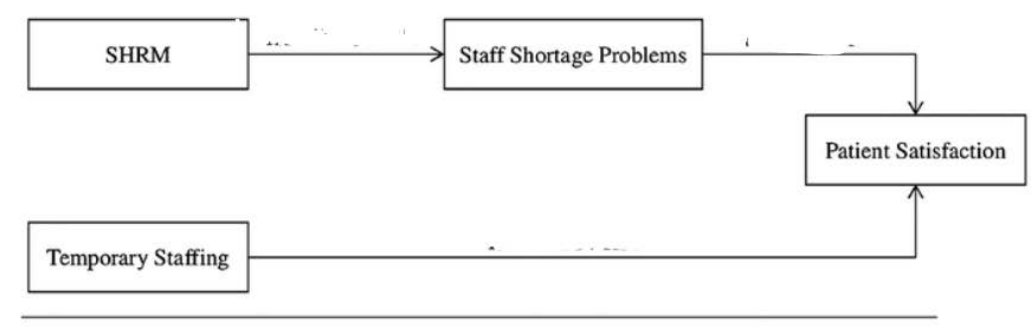

Note. SHRM = Strategic Human Resource Management.

\section{Figure 2. Theoretical model for improving patient satisfaction}

Source: adapted from Wild et al. (2017, p.58)

Another study conducted in the hospital system (Ott, 2005), on a sample of 3,542 patients and 12,193 employees, highlighted the correlation between human resource management and patient satisfaction based on the characteristic features of human resource management such as employee satisfaction at work, on the employees' performances but the most important being the staff's training.

The World Health Organization (2016) has tried through various projects to support the importance of good human resource management and implicitly the importance of specialists in hospital systems. Health systems cannot function without medical staff, and the improvement of health provided by health systems and the realization of patients' right to a good level of health depends largely on the availability and quality of medical staff (World Health Organization, 2016). The importance of human resources in hospital systems was even discussed at the United Nations General Assembly, the goal being to increase the recruitment of medical specialists, improve them, train them, and, very importantly, keeping them from leaving developing countries, especially in underdeveloped countries, this being a goal of sustainable development for the 2016-2030 period.

Given the brain drain phenomenon that strongly impacts the hospital sector by migrating staff to other foreign countries, we can say that motivating staff through good human resource management and successful management of health organizations is already a vital necessity for many countries, and the individual/ hospital staff is the most valuable resource of the system.

\section{ANALYSIS OF THE INFLUENCE OF HUMAN RESOURCES MANAGEMENT ON PATIENT SATISFACTION}

\subsection{Presentation of the Romanian health system}

About health services we can say that they have special features, they cannot be tested before the patient benefits from the medical service, they address a wide and complex range of clients whose needs and demands can vary greatly, are influenced by financial resources, technology as well as medical science. The importance of health services is also high due to the importance of the quality of services in all its dimensions, so we can look at quality as a universal standard when compared to the real conditions of the services we want to benefit from. Safety, patient interest, effectiveness, punctuality and team are components of the quality of the health service (Hasegawa \& Karandagoda, 2013).

So when we talk about the quality of medical service we think about both the accuracy of the diagnosis and treatment, and about the human factors of health care, namely the social relationship between the patient and the medical specialist. It also refers to the waiting time of the patient and the continuity of medical care.

In order to connect to the current context of the Romanian health system and to understand its evolution, I will make a brief review of its significant transformations. 
Romania has undergone over time numerous health system reforms since 1989, marked by major changes in the entire system, the 2002 reform when exceptions to the payment of contributions to the health insurance budget were introduced, the 2006 reform which wanted to increase financial control and develop managerial capacity, the controversial 2012 project that involved the reorganization of hospitals and the development of a quality management system for health services.

The establishment of a legal framework for outlining responsibilities such as planning, organizing, coordinating and monitoring hospital activities was necessary to improve the quality of hospital services and patient safety.

Another transformation refers to the remuneration of medical staff which increased on average in 2018 by $27 \%$ compared to the previous year and 2.2 times compared to 5 years ago. This transformation is an important goal for human resource management because one of the influencing factors of human resource management is employee motivation, and, in turn, employee motivation is influenced by the level of staff remuneration. Therefore, given the legislative context, the financial motivation of the staff within the hospital system has reached a level comparable to that of comparable countries in the EU, also representing an alternative in terms of retention of medical specialists. The number of doctors who left the country in 2018 is 2,312 compared to 2,795 in the previous year (Ghiorghian, 2019). The current remuneration formula helps to improve the professional satisfaction of medical teams, a satisfaction that can also be improved by developing working conditions and environment, safety, psychological comfort. The most recent transformation is the current one in which we face the new coronavirus, a pandemic that marks a new transformation of the health system in terms of technology and skills.

In order to improve health services, action plans have been set up at EU level on the health system, such as providing patients with access to their medical records and telemedicine, recommendations on a common set of practices, supporting EU health standards, electronic health certification (European commision, 2020).

Table 1. Demographic and socioeconomic context in Romania

\begin{tabular}{|l|c|c|}
\hline Demographic factors & Romania & UE \\
\hline Population size & $19,587,000$ & $511,876,000$ \\
\hline Share of population over age 65(\%) & 17.8 & 19.4 \\
\hline Fertility rate & 1.7 & 1.6 \\
\hline Socioeconomics factors & & \\
\hline GDP per capita (EUR) & 18,800 & 30,000 \\
\hline Relative poverty rate (\%) & 23.6 & 16.9 \\
\hline Unemployment rate (\%) & 4.9 & 7.6 \\
\hline
\end{tabular}

Source: adapted from European Commission (2019)

Regarding Romania, according to statistics on demographic factors, the population of our country has 19,587,000 inhabitants for which analyzes show that although since 2000 and until now life expectancy has increased from 71.2 years to 75.3 years in 2017, Romania has among the lowest life expectancy in the EU, the EU average being 80.9 years, so a difference of about 5 years in our lives of the inhabitants of this country, which we do not benefit from due to an inadequate health system. 
According to the European Consumer Health Index of 2018, we notice that Romania has the weakest health system in Europe, for completing the index were used questionnaires completed by patients and aimed at patients' rights and information, waiting time for treatment and prevention. The European Commission in its reports highlights Romania both in 2018 and in 2019 as the country with the largest discrepancies between life expectancy among men and women.

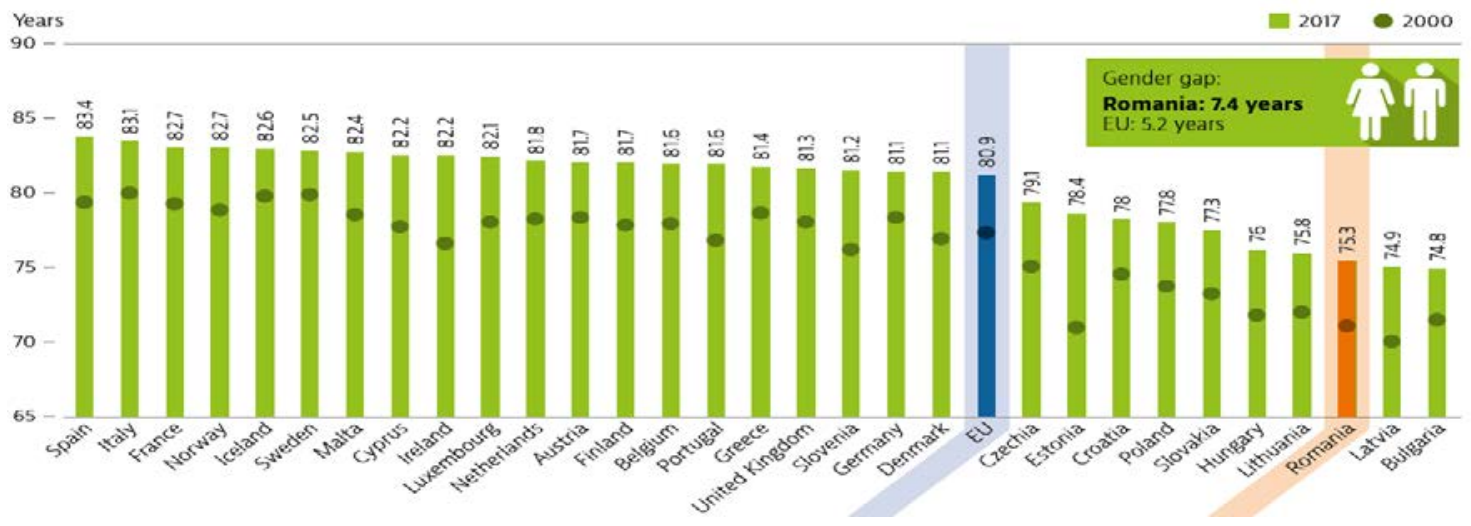

Figure 3. Life expectancy in Romania is amoung lowest in the EU Source: adapted from European Commission (2019)

The study also shows that Romania ranks last in the EU in terms of health spending, with only 983 euros per capita per year, at the opposite pole being Norway with over 4,000 euros per capita while the EU average is almost 2,773 euro.

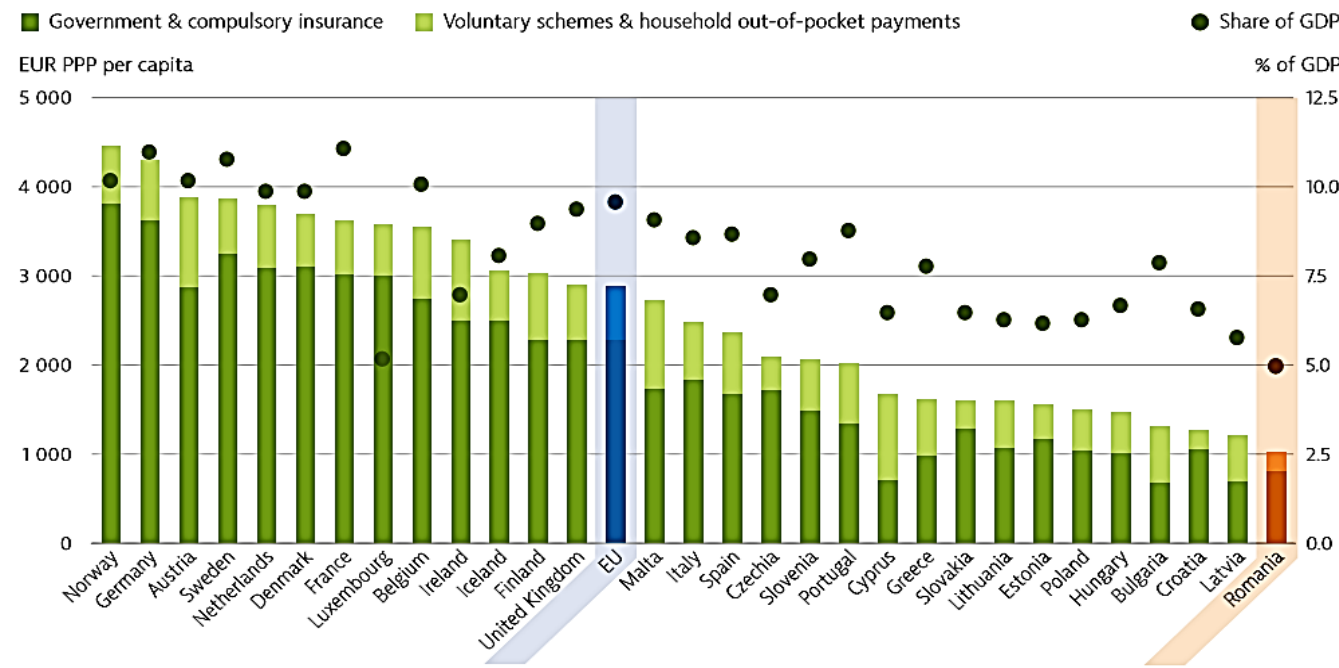

Figure 4. Health spending is lower in Romania than in any other EU country Source: adapted from European Commission (2019)

In the chart below we can see that Romania is at an alarmingly large difference from the European average in terms of the effectiveness of medical services, one of the factors influencing the quality of hospital services. This is explained by a much higher mortality rate than the European average, deaths that could have been avoided either by proper treatment or by preventive methods. 


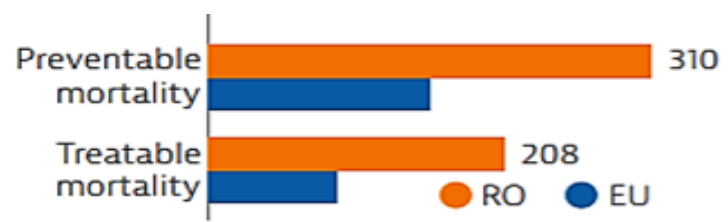

Figure 5. Age standardisation mortality rate per 100,000 population

Source: adapted from European Commission (2019)

Premature mortality is another point to improve for the hospital system in Romania and one of the solutions aims at access to medical services, an important and difficult goal to achieve due to the uneven distribution of specialists by regions of the country. If in the Bucharest-Ilfov region the country has 5.53 doctors per 1,000 inhabitants, in regions such as the north-east or south-east, the number of doctors barely exceeds 2 per 1,000 inhabitants.

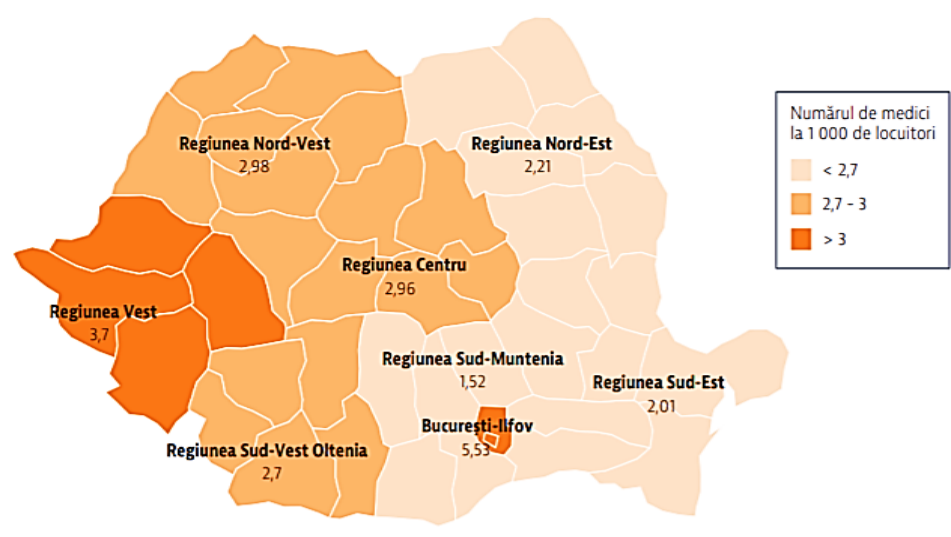

Figure 6. Uneven distribution of doctors in Romania

Source: adapted from European Commission (2019)

European statistics show that from 2007 to February 2013, Romania lost 28,000 doctors and 17,000 nurses (Ciurea et al., 2014), so another area for improvement is the brain drain phenomenon and one of the methods by which this phenomenon could be reduced among healthcare professionals could be the involvement of specialists from the hospital system in medical centers where they can benefit from conditions and resources similar to those in developed countries so that they can offer treatments to patients at high-quality standards (Gheorghian, 2019).

In conclusion, these indicators of analysis of the Romanian health system show that it is at a standstill and needs immediate remedial measures because the price of these deficiencies can be reflected in the number of lives saved.

For this, the management of human resources can support the Romanian health system by implementing measures aimed at improving the quality of medical services and also improving patient satisfaction with the services they receive.

Recent research shows that some of the solutions that could improve the quality of medical services bring to the forefront the management of the hospital sector because of good management of human resources based on leadership that requires vision, dedication, concern for people, seriousness, knowledge, professionalism, experience, permanent efforts, all this leading to the well-being of the medical team and their continuous development (Copcă, 2020).

From the specialized studies presented in the previous chapter, we know that staff ruptures directly affect patient satisfaction, so the uneven territorial distribution of specialists in Romania is one of the factors that prevent obtaining patient satisfaction. 
The alarming number of deaths in Romania can be explained by a low quality of hospital services. Drawing a parallel with specialized studies we mention the correlation between patient satisfaction and the quality of services, according to the model developed by Huan-Ming Chuang, Mao Jen Liu (2015), thus being able to explain the existence of an increased mortality rate and low life expectancy.

In conclusion, human resource management strategies can help improve the health system in Romania by increasing patient satisfaction which will be reflected in an improvement in the quality of medical services.

\subsection{The contribution of human resources management to improving patient satisfaction, beneficiaries of health services}

Over time, numerous studies have been conducted on the quality of medical services. The researchers suggest that the essence of the challenge regarding the quality of medical services is the lack of effective leadership and good human resources practices at the local level. In the United States, where there is a significant shortage of medical staff, especially in nurses, studies have shown that reducing the mortality rate in hospitals is attributed to the following factors: medical practice (King et al., 2013). Also, the reactivity of human resources management to patient-related problems has a strong impact on the quality of medical services. Studies in the United Kingdom (West et al, 2006) have also found many positive correlations between low mortality and human resource management factors such as: performance appraisal, teamwork, training and hospital staff development (Cooke \& Bartram, 2015).

Another factor in human resource management that plays an important role in the hospital sector is proactive work behavior. We analyzed how proactive work can mediate the relationship between staff capacity and quality of health services, for this we analyzed the relationship between staff capacity in the hospital sector to service quality, the relationship between proactive staff work and service quality, and indirect relationships among the capabilities of the staff in relation to the quality of services. The importance of the study was to gain a better understanding of the mechanism by which employee motivation impacts the quality of health services provided to patients. The result of the study came to support the crucial role that human resources management has on the quality of hospital services, highlighting that the positive relationship between staff capacity and service quality is mediated by the proactive behavior of staff in the hospital sector (Khatri et al., 2017).

In recent decades technology has changed a lot, the so-called "fourth industrial revolution" after steam technology, mass production and electronics, technology gives rise to a wide range of applications, some of which can be used in HR management. The latest studies on HR technology in the healthcare sector are limited to technologies such as artificial intelligence, or technological transformations related to the way an organization works and management, including: accelerating HR management systems and cloud-based solutions, introducing a continuous performance management process, reinventing learning, innovation in the field of recruitment, innovations at the HR level.

The conventional technology generally used among the hospital sectors for communication is that using mobile phones, representing both a very high cost and an outdated procedure. But young people employed in the health sector are very familiar with new devices and applications to streamline communication and collaboration. The world's first health organization, Tan Tock Seng Hospital in Singapore, said after using the Facebook workplace that their daily tasks were greatly simplified, such as requests for repairs or equipment needs, maintaining communication between trainers and students, performing surveys among employees, public thanks to employees. The result obtained through this implementation in the field of human resources management was that the employees considered that it helps both the hospital in achieving the professional objectives and that of serving and treating the patients in a much more efficient way. 
Another influencing factor of human resource management with an impact in ensuring patient satisfaction is the evaluation of the performance of hospital staff. Some of the most common causes of this influencing factor are the lack of standard procedures, the lack of measurable objectives, and inconsistent reviews of employee performance.

For example, the implementation of an HR performance management system in one of the private health institutions in Singapore (Farer Park) resulted in the elimination of errors regarding the incorrect transmission of specific documentation or even their loss, reduction of errors due to manual interventions, and reduction of costs and improving efficiency by increasing productivity. Another functionality of the system was to be able to align the objectives of the employees with those of the hospital and to monitor in real-time the achievements of the employees (Tursunbayeva, 2019).

Cathy Martin, vice president of labor policy for a California Hospital Association, said "the most successful organizations will seek out lifelong learners, and then invest in them," which will result in "the best performing workforce and likely the best patient outcomes" (Gedeon, 2019).

Another problem often encountered in the hospital sector is not only to attract leaders in the field of health but also to identify how to retain them, and one of the solutions for this problem is that of leadership development. To attract new talent, human resources management must provide candidates with a concrete vision of the professional development plan as well as leadership opportunities. In order to retain valuable specialists, a solution would be to offer them the opportunity for continuous learning (by facilitating access to various platforms, organized training, courses, etc.) as well as by increasing their responsibilities. For this, continuous learning platforms can be used, adapted according to the module that the medical staff wants to go through and depending on the type of learning chosen, face to face type teacher-student or self-taught through video mix, and finally the stage of measuring the level of knowledge acquired by the student follows so that he knows at what level of knowledge he falls and what is the next step in his axis of progress (Gedeon et al., 2019).

At the EU level, some countries have begun to develop a constant eHealth environment in a digital transformation through various tools to support the health sector to improve the quality of health services, such as applications that are classified by EU regulations as medical devices (European Commision, 2019). With the help of such applications, the staff in the hospital sector can request training to support them in their continuous training, to support the management by integrating these digital tools and to verify the data obtained with their help in their daily practice for to monitor the activity of the employees and the level of training. Through the eHealth project, numerous measures have been taken to accelerate the transformation of the health system through digitization, by developing platforms for electronic medical records as well as for e-prescriptions.

Another example of an application developed to support human resource management is called "employee voice," an application with multiple features such as the ability of the employee to provide constant feedback on both the activity and the organization or team, is an employee tracking app developed in the US that developers say provides the "right place at the table" for human resource management. It is a solution that can be applied in any field of activity, which can be used to facilitate short and long term decision making by the management of organizations by issuing predefined questionnaires for the board of the organization such as "what impact does employee engagement have on critical employee behaviors and the organization "," how we can enlist our leaders in increasing customer satisfaction," questionnaires designed to help them position themselves towards the organization's objectives, to help them coordinate employees by involving them in decision making.

These digitalization strategies pave the way for innovation, also taking into account its side effects, they are necessary transformations to allow the digital age to penetrate as much as possible in the health system, coming to the aid of both specialists and patients. 
Based on the information obtained from the literature, the analysis of the Romanian health system and the news on human resources management, I set the following priority actions to enhance the role of human resources management to improve patient satisfaction and quality of health services:

- the implementation of a strategy for measuring customer satisfaction by applying a questionnaire sent by SMS or e-mail and centralizing them on the online platform;

- the implementation of a tool to count the free, anonymous opinions of the hospital staff towards the climate within the hospitals, towards the attitude of the colleagues as well as of the management, towards the satisfaction at the workplace;

- establishing clear and well-defined working procedures to support new employees, so that they can quickly adapt to the work environment in order to provide an activity that allows patient satisfaction;

- the implementation of an application at territorial/ county/sectoral level through which to monitor the number of specialists to ensure a uniform distribution of specialists;

- the implementation of a methodology regarding the attitude that the hospital staff must have towards the patients;

- the introduction of a continuous training system for specialists, which ensures linear concordance with the new methodologies to be used for the health sector, with the annual obligation to review and evaluate the knowledge acquired to ensure the competence of hospital staff to obtain a improvements in the quality of health services;

- the elaboration of a guide for emergencies/force majeure, to be constantly reminded (at least every 6 months) to all employees, so that in case of a situation of force majeure each employee knows concretely what are his duties;

- the involvement of medical specialists who have obtained very good results in new projects or by involvement in dealing with complex cases, to help increase the motivation of employees and retain specialists;

- the implementation of a transparent communication within the hospitals, with the help of IT platforms so that all the managerial decisions, as well as the objectives of the organization, are known by each employee in real-time;

- the digitalization of specific medical documentation such as medical prescriptions, medical certificates, analysis results, etc.

\section{CONCLUSIONS}

The results of the study highlight patient satisfaction as being in a direct relationship with human resource management through the influence of specific factors of human resource management such as employee competence, employee job satisfaction, employee performance, employee attitude, employee motivation.

This study proposes a series of priorities that can be considered relevant for the management of human resources in the health sector, aiming to improve patient satisfaction by:

- the use of new IT technologies for the development of platforms for human resources management to help with the continuous training of employees, to monitor their performance;

- elaboration of a series of internal procedures, which will help improve the organization of human resources as well as to facilitate their adaptation to the working environment;

- streamlining specific processes for human resources management, by facilitating internal and external communication with the help of social platforms known as enterprise connectivity platform;

- the development of a special regulation for the management of emergency situations such as the pandemic period, in which the responsibilities of the employees should be explicitly described and which can be easily accessed online, at any time, by every employee; 
- the involvement of specialists with outstanding merits in new projects or in the treatment of complex cases - a process that can help increase the motivation of employees in order to retain specialists;

- improving effectiveness by digitizing the documentation specific to the healthcare system.

This study is a preliminary stage for a scientific research paper focused on the management of human resources in the health sector that aims to help design a model of the relationship between patient satisfaction and human resources management.

I will continue the analysis with an in-depth research on the shortcomings currently present in the management of human resources, so it can reach its full potential in terms of influencing the quality of hospital services in a positive way. The research paper involves the following steps: a quantitative and qualitative validation of the designed model, a research on patients' perception of service quality and managerial competence by analyzing influencing factors such as their knowledge and behavior, and finding a set of solutions that make use of the specialists' competency in order to increase the quality of health services.

\section{REFERENCES}

Bowen, D. (1996). Market focused HRM in service organization: satisfying internal and external customers. Journal of market-focused management, 1 , 31-47. Retrieved August 28, 2020, from https://link.springer.com/article/10.1007\%2FBF00129602.

Brînduşoiu, C. (2012). Recrutarea şi selecţia angajaţilor. Bucharest: Editura ASE.

Charles-Pauvers, B. (2020). Employee turnover: HRM challenges to develop commitment and job satisfaction. In: Shape of Tourism Employment, 55-66. doi:10.1002/9781119751342.ch4.

Chuang, H.M., Liu, M-J. \& Chen, Y-S. (2015). The effects of human resource capability and internal customer satisfaction on organizational effectiveness. International Journal of Distributed Sensor Networks, (7), 1-10, doi:10.1155/2015/835194.

Ciurea, A., Ples, H. \& Avram, E. (2014). Managementul în sistemul de sănătate privat. Bucharest: Editura Universitara.

Cooke, F. \& Bartram, T. (2015). Human resource management in health care and elderly care: current challenges and toward a research agenda. Guest editor's introduction, 711-735. doi: 10.1002/hrm.21742.

Copcă, N. (2020). O viziune modernă asupra leadershipului serviciilor spitaliceşti la nivelul municipiului Bucureşti. Bucharest, (Unpublished doctoral dissertation, Bucharest University of Economic Studies, Bucharest, 2020) p. 175. Retrived from https://rei.gov.ro/index.php?\&sm=\&ddpN=1837415839\&we=7de50869e17bec77664920c1aea e1a47\&wf=dGFCall\&wtok=\&wtkps=S7QytqouBhJKxZkpStbFVqZGVkrGyQalOdnJuRUZGd mWZgVGpUUZqXml2empVWkFRVnp+cYFxQVGuhmFxpbFBrqG5kWJyemGIL1ArdmFY AbQPCU3XWdHXWNDCwszfQNDPUMDPSMDIwMlqLryVCVrP+taAA==\&wchk=55ef84 3b2286fc2f61539a55a933b8d947029939

Deaconu, A., Podgoreanu, S. \& Raşcă, L. (2004). Factorul uman şi performanţele organizaţiei. Bucharest: Editura ASE.

Dogaru, M. \& Zaharia, V. (2016). Managementul resurselor umane si munca in echipa. Bucharest: Editura Universitara.

European Commission. (2019). State of health in the EU companion report 2019. Brussels.

European commission. (2020). Europe 2020 - for a healthier EU. Brussels.

Forza, C. \& Filippini, R. (1998). TQM impact on quality conformance and customer satisfaction: a casual model. International Journal of Production Economics, 10, June, 1-20. Retrieved September 25, 2020, from https://www.sciencedirect.com/journal/international-journal-ofproduction-economics/vol/55/issue/1. 
Gedeon, D., Anderson, C., Coring, C. \& Dobberovsky, S. (2019). A healthcare organizations guide to modern L\&D, Healthcare development guidebook, 1-21. Retrieved September 2, 2020, from https://www.cornerstoneondemand.com/sites/default/files/HealthcareDevelopmentGuidebook.p df.

Gheorghian, R. (2019, May 23). Peste 150 de medici au revenit în spitalele din România. Stiri pe surse. Retrieved September 3, 2020, from https://www.stiripesurse.ro/sorina-pintea-pune-totulpe-seama-salariilor---peste-150-de-medici-au-revenit-in-spitalele-din-romania_1352323.html.

Hasegawa, T. \& Karandagoda, W. (2013). Changement de management pour l' hôpital. Retrieved September 20, 2020, from https://www.jica.go.jp/activities/issues/health/5S-KAIZEN-TQM02/ku57pq00001pi3y4-att/text_f_01.pdf.

Khatri, N., Gupta, V. \& Varma, A. (2017). The relation between HR capabilities and quality of patient care: the mediating role of proactive work behaviors. Human Resource Management, 673-691. doi: 10.1002/hrm.21794.

Kiger, P. (2002). Why customer satisfaction starts with HR, 8, August, 26-32. Retrieved August 28, 2020, from https://www.workforce.com/news/why-customer-satisfaction-starts-with-hr.

King, D., Wei, Z. \& Howe, A. (2013). Work satisfaction and intention to leave among direct care workers in community and residential aged care in Australia. Journal of Aging \& Social Policy, 301-319. doi:10.1080/08959420.2013.816166.

Marshal, G., W., Baker, J. \& Finn, D. (1998). Exploring internal customer service quality. Journal of business \& industrial, 381-391. doi:10.1108/08858629810226681.

Mohrw-Jackson, I. (1991). Broadening the market orientation: an added focus on internal customers. Human Resource Management, 455-467. doi:10.1002/hrm.3930300403.

Ostroff, C. (1992). The relationship between satisfaction, attitudes, and performance: An organizational level analysis. Journal of Applied Psychology, 77(6), 963-974.

Ott, M. (2005). Effect of HRM on client satisfaction in nursing and care for the elderly. Employee Relations, 413-424. doi: 10.1108/01425450510605723.

Radu, E., Tigu, G., State, O. \& Tuclea, C. (2003). Managementul resurselor umane. Bucharest: Editura Expert.

Rogers, J., Clow, K. \& Klas, T. (1994). Increasing job satisfaction of service personnel. Journal of services marketing, 14-26. doi:10.1108/08876049410053267.

Rogg, K., Schmidt, D. \& Shull, C. (2001). Human resource practices, organizational climate, and customer satisfaction. Journal of Management, 431-449. doi:10.1177/014920630102700403.

Rusu, C. \& Voicu, M. (2001). Managementul resurselor umane în asigurarea calităţii. Bucharest: Editura Economica.

Torrington, D. (2003). Priorităţi tehnologice in economia românească. Retrieved September 5, 2020, from http://www.management.ase.ro/reveconomia/2003-1/19.pdf.

Tursunbayeva, A. (2019). Human resource technology disruptions and their implications for human resources management in healthcare organizations. BMC Health Services Research, 1-8. Retrieved August 28, 2020, from https://bmchealthservres.biomedcentral.com /articles/10.1186/s12913-019-4068-3.

West, M., Guthrie, J., Dawson J., Borrill, C., S. \& Carter, M. (2006). Reducing patient mortality in hospitals: The role of human resource management. Journal of Organizational Behaviour, 9831002. doi:10.1002/job.396.

Wild, E., Witner, V. \& Schreyogg, J. (2017). Evaluating the link between human resource management decisions and patient satisfaction with quality of care. Health Care Management Review, 54-64. doi: 10.1097/HMR.0000000000000087.

World Health Organization (2016). Ressources humaines pour la santé: stratégie mondiale à l'horizon 2030. Geneva. 